Wuni et al. (2021). "Exploring the design risk factors for modular integrated construction projects". Construction Innovation. (Accepted)

\title{
Exploring the design risk factors for modular integrated construction projects
}

\author{
Ibrahim Yahaya Wuni*, Geoffrey Qiping Shen
}

Department of Building and Real Estate, The Hong Kong Polytechnic University, 11 Yuk Choi Road, Hung Hom, Kowloon, Hong Kong

\section{Maxwell Fordjour Antwi-Afari}

Department of Civil Engineering, College of Engineering and Physical Sciences, Aston University, B4 7ET Birmingham, UK

*Email: ibrahim.wuni@ connect.polyu.hk 
Wuni et al. (2021). "Exploring the design risk factors for modular integrated construction projects". Construction Innovation. (Accepted)

\title{
Exploring the design risk factors for modular integrated construction projects
}

\begin{abstract}
Purpose - Modular integrated construction(MiC) is considered as a process innovation to improve the performance of construction projects. However, effective delivery of MiC projects requires management of risks and uncertainties throughout its delivery chain. Although the design stage of $\mathrm{MiC}$ projects is usually managed with limited knowledge based on highly uncertain data and associated with epistemic uncertainties, $\mathrm{MiC}$ design risks have not received adequate attention relative to other stages. This paper conducted a knowledge-based evaluation and ranking of the design risk factors (DRFs) for MiC projects.

Design/methodology/approach - The study reviewed the relevant literature to identify potential DRFs and validated their relevance through pilot expert review. The study then used questionnaires to gather data from international $\mathrm{MiC}$ experts from 18 countries and statistically analysed the dataset.

Findings - Analysis results showed that the five most significant DRFs for MiC projects include unsuitability of design for the MiC method; late involvement of suppliers, fabricators, and contractors; Inaccurate information, defective design, and change order ; design information gap between the designer and fabricator; and lack of bespoke MiC design codes and guidelines. A correlation analysis showed that majority of the DRFs have statistically significant positive relationships and could inform practitioners on the dynamic links between the DRFs.

Practical implications - The research provides useful insight and knowledge to MiC practitioners and researchers on the risk factors that could compromise the success of $\mathrm{MiC}$ project designs and may inform design risk management. The dynamic linkages among the DRFs instruct the need to adopt a system-thinking philosophy in MiC project design.

Originality/value - The paper presents the first study that specifically evaluates and prioritizes the risk events at the design stage of $\mathrm{MiC}$ projects. It sets forth recommendations for addressing the identified DRFs for MiC projects.
\end{abstract}

Keywords: critical risk factors; delivery chain; design risks; modular integrated construction; project delivery; risk management 
Wuni et al. (2021). "Exploring the design risk factors for modular integrated construction projects". Construction Innovation. (Accepted)

\section{Introduction}

Modular integrated construction (MiC) is considered as a disruptive construction method to improve the competitiveness of the construction industry and project performances in terms of productivity, safety, schedule, quality, cost, material waste, efficiency and predictability (Horner et al., 2019; van Vuuren and Middleton, 2020). MiC employs more innovative processes and techniques where significant aspects of a project are manufactured offsite as modules, in a controlled factory environment and transported to the construction site for installation and integration with minimal onsite works (Sutrisna et al., 2018). Incorporating a best production design principles (e.g. design for manufacture and assembly) along with the controlled factory environment allows for upstream construction challenges to be planned and resolved early upfront to reduce risks in construction projects (KPMG, 2016).

The reluctance of construction stakeholders to implement modular solutions in their projects has been linked to the perceived inadequacy in dealing with risks in projects implementing modular solutions (Wuni and Shen, 2020a). So, an in-depth understanding of the delivery challenges, risks, and issues could enable construction projects to gain full benefits from implementing modular solutions. From a construction project management perspective, risks are inevitable (Baloi and Price, 2003) and must be managed throughout the delivery chain to realize planned objectives and the expectations of stakeholders. As such, risk management in construction projects is considered as a critical success factor and an integral component of construction project governance (Project Management Institute, 2017).

Risk management provides a holistic approach to understanding the occurrence, interactions, and impact of risks on MiC projects (Nibbelink et al., 2017; Sutrisna and Goulding, 2019). However, existing risk management studies have mostly examined general risks associated with MiC projects. The holistic approach has the tendency of masking the significant variations of the 
Wuni et al. (2021). "Exploring the design risk factors for modular integrated construction projects". Construction Innovation. (Accepted)

risk factors across the different phases of the MiC project delivery chain (Sutrisna and Goulding, 2019). It has been established that successful delivery of MiC projects hinges on effective management of the early phases of the project lifecycle (Wuni and Shen, 2020b). Notably, effective MiC project design management is considered as an essential precursor for realizing the full benefits of using modular solutions in construction projects (Blismas and Wakefield, 2009).

At the early stages, the project data and information required to inform the design are usually estimated and such estimates contain some margins of errors and uncertainty. Thus, the design of MiC projects is executed and managed with limited knowledge based on highly uncertain data. Moreover, the design stage has systemic implications on the entire project because the design specification regulates and informs the decisions at downstream segments of the delivery chain. Thus, epistemic uncertainties at the design stage could generate systemic risks in MiC projects, instructing the need to use accurate, complete, and quality design information to reduce the epistemic uncertainties in the design process (Nibbelink et al., 2017; Sutrisna and Goulding, 2019). The uncertainties associated with the design stage are considered "wicked problems" because the risk events are complex, systemic, ill-structured, difficult to address and their primary sources are obscure to comprehensively defined (Buchanan, 1992).

Despite the wicked problems and associated systemic implications, MiC design risks have received little research attention relative to other stages (Nibbelink et al., 2017). To this end, this paper seeks to investigate the design risk factors (DRFs) for MiC projects. Considering that the opinions and views of experienced project participants are usually leveraged in risk planning and management (Project Management Institute, 2017), this paper draws on the opinions of international MiC experts to evaluate the DRFs for MiC projects. The findings could provide useful insight into the DRFs and facilitate more informed and structured risk management at the 
Wuni et al. (2021). "Exploring the design risk factors for modular integrated construction projects". Construction Innovation. (Accepted)

design stage of MiC projects. The rest of the paper is structured as follows. The next section provides an overview of $\mathrm{MiC}$ design and associated risk factors, followed by a description of the research methodology. The paper proceeds with a presentation of the results, followed by discussions of key findings and implications for risk management. Conclusions are then drawn, and the limitations of the research are acknowledged in the last section.

\section{Background}

\section{Overview of the $\mathrm{MiC}$ project design}

Offsite manufacturing, offsite construction, industrialized construction, manufactured construction, prefabricated prefinished volumetric construction, and offsite production are similar modern methods of construction and refer to $\mathrm{MiC}$ in this research. Although there are subtle differences between these terminologies, it is beyond the scope of this research and can be found elsewhere (Ayinla et al., 2019). A typical MiC project delivery chain involves conceptualization, design, planning, offsite production, handling, and transportation of components, on-site works, and installation (Sutrisna and Goulding, 2019).

MiC project design is significantly different from traditional construction project design (Gao et al., 2019). First, the design of MiC projects is based on the concepts of modularity, modularization, complex systems, and design for excellence. It has been recognized that MiC alone cannot deliver the performance improvements required in construction projects, unless they employ integrated design processes such as design for manufacture and assembly, DfMA (KPMG, 2016). The use of DfMA in MiC projects avoids the concept of 'over-the-wall' syndrome (Boothroyd, 1994) where manufacturers have to deal with challenges associated with design errors because they are a part of the design team and usually address manufacturing and assembly constraints early upfront at the design stage (Gao et al., 2019). Second, MiC project design is 
Wuni et al. (2021). "Exploring the design risk factors for modular integrated construction projects". Construction Innovation. (Accepted)

associated with stricter increasing inflexibility as the design development progresses (Sutrisna and Goulding, 2019). Changes are both expensive and difficult to implement at some stages of the design development, especially after the design freeze and initiation of the offsite production of the units. Third, there is the requirement for an early design freeze to proceed with the timely production of the components to meet the tighter schedules of MiC projects. Failure to complete and freeze the design early could be counterproductive to the benefits of the MiC method in a project. These unique design requirements hatch several risks events and factors that must be considered for effective design management in $\mathrm{MiC}$ projects.

\section{Theoretical checklist of MiC DRFs}

Although there are no existing studies that have specifically identified, evaluated, and ranked the DRFs for MiC projects, relevant design risk factors have implicitly documented in the literature. Table I presents a checklist of 20 potential design risk factors identified in the literature. The various categories of the risks are discussed next.

[Table I. Checklist of DRFs for MiC projects]

Design information quality risks. Some of the documented DRFs are linked to poor quality and inadequacy of the design information. According to Nibbelink et al. (2017), inaccurate design information or data constitutes the fundamental source of errors and reworks in the working drawings. Sutrisna and Goulding (2019) corroborates the position of Nibbelink et al. (2017) and indicated that incomplete and inaccurate design data results in systemic errors that can be propagated throughout the delivery chain if unrectified and unresolved. The bullwhip and spillover effect of the inaccurate design information is inaccurate working drawings (Li et al., 2017). Lee and Kim (2017) further documented that poor design data results in an unclear detailed design 
Wuni et al. (2021). "Exploring the design risk factors for modular integrated construction projects". Construction Innovation. (Accepted)

specifications and documents. A cause of the inaccurate and incomplete design data is inadequate design planning (Nibbelink et al., 2017). Nibbelink et al. (2017) also identified that late involvement of suppliers, fabricators, and contractors in the project can negatively influence the quality of design information.

Late design completion. The expedited project delivery outcomes in MiC projects largely depends on timely completion and freezing of the detailed design (Wuni and Shen, 2020b). The literature documented risk factors linked to late design completion. According to Gibb and Isack (2001), the inability to complete, approve, and freeze the detailed design early contributes significantly to late design completion. Li et al. (2016) added that inefficiency design approval can extend the design lead time and delay completion. Enshassi et al. (2019) concluded that redesign due to errors can increase the design time and delay completion. Li et al. (2017) support the positions of Enshassi et al. (2019) that late design changes constitutes a chief driver extended design completion time. Several reasons can impose late design changes, but a major cause is the failure of the working drawings to meet the performance requirements after a mock-up test (Lee and Kim, 2017).

Poor design and reworks: Poor design quality and design reworks can negatively affect the schedule, cost, quality, and satisfaction of stakeholders of MiC projects (Li et al., 2017). Design reworks can increase design costs and lead time (Nibbelink et al., 2017). Failure of the design team to specify and incorporate adequate lateral force resisting system in the structural design can compromise the integrity of high-rise MiC projects (Lee and Kim, 2017). A defective design may also arise from over design for materials and structural members as well as failure to incorporate fire and seismic resistance standards in the working drawings (Lee and Kim, 2017). Wuni and Shen (2020c) added that dimensional and geometric variabilities in the module design 
Wuni et al. (2021). "Exploring the design risk factors for modular integrated construction projects". Construction Innovation. (Accepted)

specifications results in a terribly defect design, which could result in mass production error-laden modules if unresolved before the working drawings arrive at the factory production stage.

The foregoing literature synthesis indicates that prevailing studies have recognized the existence and importance of DRFs for MIC projects. Although considerable effort has been made to discuss DRFs, none of them specifically identified and prioritized the DRFs for MiC projects. However, the review of the existing MiC risk management studies provides a good reference for this study to identify the DRFs for MiC projects. Table I formed the basis for establishing a list of relevant DRFs for MiC projects for further action in the study.

\section{Research methods}

The paper used a knowledge-based expert approach to evaluate the DRFs for MiC projects and as a recommended practice, utilized expert knowledge rather than past data from implemented MiC projects (Hwang et al., 2018). This expert approach is considered suitable because risk identification, evaluation, and prioritization in construction projects draw on the informed assessment of experienced construction professionals (Project Management Institute, 2017). As such, the survey research approach was employed to gather the opinions of domain practitioners and academics in evaluating the DRFs for MiC projects.

The research employed a four-phase methodological framework. In phase 1, a comprehensive review of relevant literature was conducted to determine their deficiencies in informing MiC project design management and to develop a checklist of DRFs for MiC projects. Phase 2 involved recruiting relevant domain experts to evaluate the DRFs for $\mathrm{MiC}$ projects. Phase 3 involved development of a measurement instrument and questionnaire survey to gather the opinions of the 
Wuni et al. (2021). "Exploring the design risk factors for modular integrated construction projects". Construction Innovation. (Accepted)

expert panel. Phase 4 analyzed the gathered data using appropriate statistical techniques. The four phases of the research methodology are described below.

\section{Comprehensive literature review}

The research started with a comprehensive review of the MiC risk management literature and forms part of a larger research project that seeks to develop a best practice framework for implementing MiC projects. The literature research was implemented to spot the deficiencies and limitations of using existing risk management literature to guide $\mathrm{MiC}$ project design management. Through the review, ten relevant DRFs were recruited. Three experienced international MiC experts from both academia and industry were invited to review the identified DRFs to ascertain their representativeness, adequacy, clarity, and practical relevance. The experts shortlisted ten of the DRFs in Table 1 and proposed two additional DRFs. They also suggested modifications in the descriptions of some DRFs. Table II summarizes the final list of twelve DRFs for MiC projects that formed the basis of the data collection in this study.

[Table II. Final lists of DRFs for IC projects]

\section{Recruitment of relevant international MiC experts}

The paper employed the expert (purposive) sampling approach to recruit the target MiC experts. This sampling technique has been widely used in international survey studies in construction management when there is no centralized database of the target population (Wuni and Shen, 2020b). The expert sampling approach was appropriate for recruiting the international experts in this paper due to the following reasons. First, MiC has only gained renewed interest and momentum during the last 3 decades with fewer domain researchers and countries reporting 
Wuni et al. (2021). "Exploring the design risk factors for modular integrated construction projects". Construction Innovation. (Accepted)

research findings and piloting projects, respectively. As such, MiC experts are not ubiquitous and without a centralized database to support probabilistic sampling (e.g. random sampling). Second, the bespoke and esoteric nature of design risks require the use of experts with adequate hands-on and research experiences in $\mathrm{MiC}$ project delivery.

For these reasons, the expert sampling technique was deemed suitable and was employed to select the international experts based on the following criteria. First, the respondent should have in-depth knowledge of MiC project risks. Second, the respondent should have adequate hands-on experience or case study research experience in MiC project delivery. Third, the respondent should have been involved in at least one $\mathrm{MiC}$ project implementation (Ameyaw and Chan, 2015). These criteria were predefined to ensure that the selected $\mathrm{MiC}$ experts had relevant knowledge to provide reliable evaluation of the DRFs for MiC projects. Based on the criteria, a total of $400 \mathrm{MiC}$ experts were recruited from dedicated websites of construction industry councils, institutes, and authorities in 18 countries and $\mathrm{MiC}$ related research publications in academic journals, conference papers, and workshop reports. Although there is no universal sample frame for international survey studies, the 400 was considered adequate and higher than the sample frames in previous international survey studies such as 200 (Zhang, 2005) and 310 (Osei-Kyei et al., 2017). A database containing the contact emails and names of the 400 experts was created in a Microsoft Excel sheet and used for the data collection.

\section{Measurement instrument and questionnaire survey}

The paper deployed an online-based questionnaire survey to collect the relevant data. MiC risks have been predominantly evaluated using questionnaires because it is an effective instrument for gauging the perceptions of experts about the impact of the risk events and can also reveal 
Wuni et al. (2021). "Exploring the design risk factors for modular integrated construction projects". Construction Innovation. (Accepted)

correlations in their perceptions (Ameyaw and Chan, 2015). The questionnaire contained two sections. Section 1 was dedicated to collecting relevant data of the respondents to verify and validate the selection criteria. Section 2 requested the experts to evaluate the significance of the DRFs for MiC projects. It employed the Likert scale as a tool to assess the relative significance of the DRFs for MiC projects. Although5-, 7-, and 9-point rating scales are commonly used in construction management research (Wuni et al., 2020), this research used the 5-point Likert scale because it is the commonest used rating scale, widely understood by construction management academics and industry practitioners, reduces the cognitive complexity associated with longer scales, and has proven consistent in generating reliable survey-based data (Ameyaw and Chan, 2015). The impact of risks on construction projects is commonly measured as a product of its severity and probability (Ameyaw and Chan, 2015). Thus, it would have been fundamental to collect data on the probability and severity of the DRFs for MiC projects, but it is also appropriate to directly measure the significant of a given set of risk factors in construction projects (Wuni et al., 2020). Consequently, the experts were requested to evaluate the significance of the DRFs for MiC projects based on a 5-point rating scale (1=very insignificant, $2=$ insignificant, $3=$ slightly significant, 4=significant, and 5=very significant). Considering the detrimental impact of negative risks, any DRF assessed as 'slightly significant' was considered critical .

The questionnaire was transformed into an online-based survey form using the "Survey Monkey" platform and the link to the survey was extracted. Using the database of the 400 experts, personalized emails were sent to each expert, inviting them to complete the survey within 4-weeks. After two rounds of reminders, a total of 56 valid responses were received, representing a low response rate of $14 \%$. However, the sample size was considered adequate because it exceeded the minimum requirement of 30 valid responses of the central limit theorem for valid statistical 
Wuni et al. (2021). "Exploring the design risk factors for modular integrated construction projects". Construction Innovation. (Accepted)

conclusions (Ott and Longnecker, 2016). Moreover, lower sample sizes and response rates are characteristics of international survey studies in construction management (Osei-Kyei et al., 2017). Finally, the 56 valid responses were reasonable and higher than sample sizes in some published international survey-based studies such as 42 (Osei-Kyei et al., 2017) and 46 (Zhang, 2005).

\section{Methods of statistical pre-testing and analysis}

Given the smaller sample size, the dataset was pre-tested for reliability and validity prior to the main statistical analysis. The Cronbach's Alpha was used to measure the internal consistency and reliability of the dataset. Alpha values are between 0.0 to 1.0, but the minimum acceptable Alpha for reliable dataset is 0.7 (Ott and Longnecker, 2016). The normal distribution of the dataset was pre-tested using the Shapiro-Wilk test to ascertain the suitability of using parametric or nonparametric statistical techniques to analyze the dataset. The dataset was found to be non-normally distributed $(p>0.05)$, instructing the use of non-parametric techniques to analyze the dataset. As such, the Mann-Whitney U-test was used to determine whether there are statistically significant variations between the responses of the experts from academia and industry. Subsequently, descriptive statistical techniques including arithmetic mean, standard deviations, and weighting functions were used to prioritize the most significant DRFs for MiC projects. The mean significance index $\left(\mathrm{MS}_{\mathrm{i}}\right)$ and weighting $\left(\mathrm{W}_{\mathrm{i}}\right)$ of each DRF for MiC projects were computed using equations (1) and (2), respectively.

$$
\begin{aligned}
& \mathrm{MS}_{\mathrm{i}}(\mu)=\frac{\sum(\mathrm{E} \times \mathrm{F})}{\mathrm{N}} \\
& \text { Weight }\left(\mathrm{W}_{\mathrm{i}}\right)=\frac{\mathrm{MS}_{\mathrm{i}}}{\sum_{\mathrm{i}=1}^{\mathrm{M}} \mathrm{MS}_{\mathrm{i}}}
\end{aligned}
$$

$\mu=$ the mean significance index of a DRF

$\mathrm{E}=$ the number of ratings (i.e. 1-5) for the DRF 
Wuni et al. (2021). "Exploring the design risk factors for modular integrated construction projects". Construction Innovation. (Accepted)

$\mathrm{F}=$ the scores assigned to a DRF by the experts ranging from 1 to 5

$\mathrm{N}=$ the total number of responses obtained by a DRF

$\mathrm{W}_{\mathrm{i}}=$ the weight of a DRF and

$\Sigma\left(\mathrm{MS}_{\mathrm{i}}\right)=$ the summation of the mean significance indices of all DRFs for MiC projects.

Finally, the paper conducted Pearson's correlation analysis to ascertain the interactions and strength of relationships between the identified DRFs for MIC projects. The Pearson correlation coefficient (r) measures the strength of a linear association between two variables and takes values between +1 and -1 (Ott and Longnecker, 2016). The Pearson correlation coefficient (r) between two DRFs was computed using equation (3).

$$
\text { Pearson's correlation coefficient }\left(r_{\mathrm{i}}\right)=\frac{\sum\left(\mathrm{x}-\mu_{\mathrm{x}}\right)\left(\mathrm{y}-\mu_{\mathrm{y}}\right)}{\sqrt{\sum\left(\mathrm{x}-\mu_{\mathrm{x}}\right)^{2} \sum\left(\mathrm{y}-\mu_{\mathrm{y}}\right)^{2}}}
$$

$r=$ the Pearson's correlation coefficient between two DRFs

$\mathrm{x}=\mathrm{a}$ DRF for MIC projects in the horizontal component of the correlation table

$\mu_{\mathrm{x}}=$ the mean of a DRF for MIC projects in the horizontal component of the correlation table

$y=\mathrm{a}$ DRF for MIC projects in the vertical component of the correlation table

$\mu_{\mathrm{y}}=$ the mean of a DRF for MIC projects in the vertical component of the correlation table.

\section{Results and discussions}

\section{Relevant information of the respondents}

The profile of the experts who participated in the survey is presented in Table III, including the sector of work, geospatial distribution, and years of experience of the experts. As shown in Table III, majority of the experts worked in academia. The dominant representation of academic experts in the research is common distribution in international survey studies and does not compromise the validity of the results. Academic experts maintain ties with industry and their publications of 
Wuni et al. (2021). "Exploring the design risk factors for modular integrated construction projects". Construction Innovation. (Accepted)

case studies research indicates that they may have both practical and research experience in MiC projects. Besides, majority of the experts had over 5 years of industrial and/or research experiences in MiC project delivery (Table III). This indicates that the experts evaluated the DRFs based on several years of working, researching, and participating in the delivery of MiC projects and lends further credence to the input data used in prioritizing the DRFs.

Table III also shows that experts from 18 countries participated in the research. This wideranging catchment and geospatial representation provided a unique and diverse knowledge base for prioritizing the DRFs for MiC projects. The dominance of experts from Asia and Pacific (33.9\%), North America (32.2\%), Europe (19.6\%) and Australia (8.9\%) augments lends further credence and reliability of the dataset because these territories are noted for their significant advancement and higher levels of MiC projects' implementation and their experts are well-placed to comment on the relative significance of the DRFs for MiC projects. The lower representation of experts from Africa and South America was due to the accessibility of fewer domain MiC experts and dedicated $\mathrm{MiC}$ councils or institutions in these continents during the expert recruitment process.

[Table III. Relevant background information of the MiC experts]

Additionally, the expert panel worked on different projects where the MiC method was used. These projects include housing/real estate (71.4\%), commercial/office facilities (30.4\%), schools/education (26.8\%), industrial projects $(23.2 \%)$, health/hospital projects (17.9\%), energy/power projects $(16.1 \%)$, transport projects $(8.9 \%)$, prisons/defence $(5.4 \%)$, water and wastewater systems $(5.4 \%)$, and other project types $(10.7 \%)$. This distribution suggests that the expert panel had worked on various types of $\mathrm{MiC}$ projects, with majority having experiences in housing/real estate, commercial/office, schools/education, industrial, and health/hospital projects 
Wuni et al. (2021). "Exploring the design risk factors for modular integrated construction projects". Construction Innovation. (Accepted)

where modular solutions were implemented. These types of projects have repetitive design features and suitable for the implementation of modular solutions (Gibb and Isack, 2001). The diversity of the projects shows that modular solutions are used for several types of construction projects and further corroborates the rising interest of the global construction community in promoting modular solutions.

\section{Pre-testing outcomes of the dataset and frequencies of responses}

The reliability analysis generated a Cronbach's Alpha value of 0.811 for the set of 12 DRFs for $\mathrm{MiC}$ projects and suggested excellent uniformity of the responses and reliability of the questionnaire. Table IV summarizes the frequencies of the responses, normality, and agreement tests results. Generally, majority of the experts rated the 12 DRFs for MIC projects as at least 'slightly significant'. As shown in Table IV, $P$-values for the Shapiro-Wilk test of normality for the 12 DRFs were significant at $95 \%$ confidence interval, indicating that the responses for each DRF were not normally distributed (Chou et al., 1998). As a result, the Mann-Whitney U test was used to measure the agreement among the responses for the 12 DRFs for MIC projects (Kim, 2015). The Mann-Whitney U test is an ordinal-based non-parametric test used to compare the statistical differences between the responses of two independent groups when the dependent variable is either ordinal or continuous, but not normally distributed (Nachar, 2008).

[Table IV. Frequencies, normality, and agreement of responses]

The asymptotic significance (2-tailed) P-values of the Mann-Whitney U test were greater than 0.05 for all DRFs (except DRF7), suggesting that there were no statistically significant variations in the 
Wuni et al. (2021). "Exploring the design risk factors for modular integrated construction projects". Construction Innovation. (Accepted)

responses of the experts from academia and industry. This implied that the responses of the 56 experts for the 11 DRFs could be treated as a holistic dataset. The $P$-value for DRF7 was less than 0.05 at $95 \%$ confidence level, suggesting that the experts had statistically significant disagreements in its evaluation and was excluded from further analysis.

\section{Ranking of the DRFs for MiC projects}

The mean significance indices, standard deviations, and weightings of the 11 retained DRFs for MiC projects are presented in Table V. Except for DRF10, the mean significance indices of the DRFs exceeded 3.0 on the 5-point rating scale, indicating that the experts evaluated 10 of the DRFs as at least 'slightly significant'. Except for DRF3, DRF5, and DRF12, the standard deviations of the remaining DRFs were higher than unity. This suggested that there were some variations between the rankings of the experts from academia and industry, but as demonstrated by the MannWhitney U test results in Table IV, the variations are not statistically significant and were ignored.

[Table V. Mean significance indices and weightings of the DRFs for MiC projects]

The research demonstrated that the experts consider the DRFs for MiC projects to have different levels of significance. Priority analysis have some implications that require consideration. Based on the mean significance indices and weightings, the six most significant DRFs for MiC projects include unsuitability of design for the MiC method (DRF12), late involvement of suppliers, fabricators, and contractors (DRF3), inaccurate information, defective design, and change order (DRF1), design information gap between the designer and fabricator (DRF8), lack of bespoke MiC design codes, guidelines and standards (DRF4), and unable to freeze design early (DRF2). These results indicate that effective MIC project design management requires evaluation of the suitability 
Wuni et al. (2021). "Exploring the design risk factors for modular integrated construction projects". Construction Innovation. (Accepted)

of the project design for modular solutions as well as early engagement of and sharing of quality design information among designers, consultants, suppliers, fabricators, and contractors to facilitate a more robust engineering specification and early design freezing. The significant DRFs for MiC projects are discussed below.

The most 'aggressive' design risk factor is the unsuitability of the design for the MiC method. The non-consideration of the suitability of the design for MiC projects is a bad design management practice that can create a condition where the MiC project fails even before the factory production of the modules commences. The full benefits of the MiC method in a project hinges on high quality and dedicated design for its usage in a project (KPMG, 2016). Thus, the design team must explicitly ascertain the compatibility of the project design with the use of modular solutions. It is a good practice to use the services of an MiC design consultant or expert at the earliest stages of the project to avoid this risk (Blismas et al., 2005). The research also further highlighted the importance of early involvement of suppliers, fabricators, and contractors in MiC project design (Nibbelink et al., 2017). Failure to involve these players at the design stage creates possibilities for the design team to overlook some critical downstream supply chain constraints at the design stage. This practice will usually require a review of the design, rectification of the potential impact of non-incorporated constraints, modifications, and freezing prior to the production of the modules, and could generate significant adverse implications on the tighter schedules of MiC projects (Wuni and Shen, 2020c).

As noted in Nibbelink et al. (2017) and Sutrisna \& Goulding (2019), if the design team feeds the design process with inaccurate and incomplete design information, the resulting output will be defective design and could trigger change order. This risk is usually high because the design stage is mostly planned with incomplete knowledge based on uncertain data. Thus, enough lead time 
Wuni et al. (2021). "Exploring the design risk factors for modular integrated construction projects". Construction Innovation. (Accepted)

should be allocated for extensive collaborative design planning with clients, contractors, suppliers, designers, and manufacturers to generate high-quality design information and optimal MiC design solution. Frequent communication and sharing of design information between members of the design team would provide opportunities for members to review, modify, and provide relevant industry inputs into the design information.

Considering that $\mathrm{MiC}$ project design requirements are different from those of traditional projects, it is crucial for the design team to confirm whether local building codes, standards, and technical guidelines supports the adoption of modular solutions and make careful reference to them when developing the detailed design. This practice is crucial because excessive design inspection and approval procedures by building authorities in some countries have proven to delay the design freezing, cascading into delays in production of modules (Li et al., 2016; Li, Shen, et al., 2017). Meanwhile, a late design freeze should be avoided because it negatively affects the modules' production lead time and schedule of the entire MiC project (Gibb and Isack, 2001).

\section{Correlations analysis of DRFs for MIC projects}

The Pearson's correlation coefficients and P-values between the DRFs for MiC projects at 95\% confidence interval are summarized in Table VI. The results show that 26 of the 55 correlations were statistically significant at $95 \%$ confidence interval, indicating that the DRFs for MiC projects have interactions. Of these, "inadequate design planning (DRF9) and inaccurate information, defective design, and change order (DRF1)", "design rework (DRF11) and inaccurate information, defective design, and change order (DRF1)", "design rework (DRF11) and design information gap between the designer and fabricator (DRF8)", and "design rework (DRF11) and inadequate design planning (DRF9)" showed strong positive correlations of $(r=0.563 ; n=56 ; p=0.000<0.05)$, 
Wuni et al. (2021). "Exploring the design risk factors for modular integrated construction projects". Construction Innovation. (Accepted)

$(\mathrm{r}=0.644 ; \mathrm{n}=56 ; \mathrm{p}=0.000<0.05), \quad(\mathrm{r}=0.640 ; \mathrm{n}=56 ; \mathrm{p}=0.000<0.05)$, and $\quad(\mathrm{r}=0.630 ; \mathrm{n}=56$; $\mathrm{p}=0.000<0.05)$, respectively. The strong statistically positive significant relationships between these DRFs for MiC projects indicate that an increase in the impact of one DRF increases the risks and impact of the correlated risk factor. For instance, failure to make extensive collaborative design planning could result in feeding the design with inaccurate and incomplete information; which constitutes sources of design defects, rework, and potential change order (Nibbelink et al., 2017; Sutrisna and Goulding, 2019).

[Table VI. Inter-item Pearson's correlations between the DRFs for MiC projects]

Similarly, failure to engage fabricators and relevant project participants early upfront in the MiC project design and ensuring design information sharing will increase the risks of design rework because of the chances for the design team to overlook critical downstream production constraints that must be addressed prior to mass production (Wuni and Shen, 2020c). These correlations corroborate findings of previous studies that the success of MiC project design hinges on the adequate design planning and the accuracy, completeness, and quality of the design information (Nibbelink et al., 2017; Sutrisna and Goulding, 2019). As shown in Table VI, the weakest positive correlation $(\mathrm{r}=0.010 ; \mathrm{n}=56 ; \mathrm{p}=0.943>0.05)$ is between "unsuitability of design for the MiC method (DRF12) and design rework (DRF11)" which was also not statistically significant $(\mathrm{p}=0.943>0.05)$.

Table VI also shows that there are statistically insignificant negative correlations between "lack of bespoke MiC design codes, guidelines and standards (DRF4) and late involvement of suppliers, fabricators, and contractors (DRF3)" $(r=-0.258 ; n=56 ; p=0.055>0.05)$, "supply chain information 
Wuni et al. (2021). "Exploring the design risk factors for modular integrated construction projects". Construction Innovation. (Accepted)

gap and inconsistency (DRF5) and late involvement of suppliers, fabricators, and contractors (DRF3)" $(r=-0.070 ; n=56 ; p=0.611>0.05)$, “design complexity (DRF6) and late involvement of suppliers, fabricators, and contractors (DRF3)" $(r=-0.031 ; n=56 ; p=0.821>0.05)$, "inadequate design planning (DRF9)" and late involvement of suppliers, fabricators, and contractors (DRF3)" $(\mathrm{r}=-0.017 ; \mathrm{n}=56 ; \mathrm{p}=0.901>0.05)$ and others. However, none of the negative correlations between the DRFs were statistically significant and the strength of the relationships was generally low. The weakest negative correlation $(\mathrm{r}=-0.011 ; \mathrm{n}=56 ; \mathrm{p}=0.936>0.05)$ is between "inefficiency in design approval (DRF10) and unable to freeze design early (DRF2)" which was also not statistically significant.

Overall, Table VI shows that majority (47) of the 56 correlations were positive, of which over $55 \%$ were statistically significant. This finding suggests that there are some significant dynamic interactions between the DRFs for MiC projects that should be considered in MiC design risk planning and management. However, majority of these DRFs have low to moderate relationships, suggesting weaker links between the DRFs. Effectively, the DRFs have either static or dynamic relationships and instruct the need to adopt systems-thinking philosophy in MiC project design to account for the risk sources, failure points, and "wicked problems" at the design stage.

\section{Theoretical, practical, and managerial contributions of the research}

This research contributes to the MiC project delivery risk management literature and practice through identifying, evaluating, and prioritizing the most significant DRFs for MiC projects as well as examining the dynamic relationships between the DRFs. As such, the findings have the following implications. First, the research provides useful insight and knowledge to MiC practitioners and stakeholders on the risk factors that could compromise the success of MiC project 
Wuni et al. (2021). "Exploring the design risk factors for modular integrated construction projects". Construction Innovation. (Accepted)

design. Thus, the paper provides evidence to inform and support effective MiC project design risk management. Second, the insights and knowledge from the correlation analysis showed some statistically significant strong positive and statistically insignificant weak negative correlations between the DRFs for MiC projects. This could inform practitioners and stakeholders on the dynamic links between the DRFs and provide useful evidence on the need to adopt a systemthinking philosophy in $\mathrm{MiC}$ project design. Finally, the findings reinforce the need to adopt collaborative design practice and allocate enough time to ensure that the team proactively considers and incorporates downstream delivery challenges into the design.

\section{Conclusions and future research}

This paper evaluated and prioritize the DRFs for MiC projects, drawing on the views and opinions of MiC experts from 18 countries. The research employed a 5-point rating scale to measure the relative significance of $12 \mathrm{DRFs}$ for MiC projects. Based on the mean significance and weighted indices, the five most significant DRFs for MiC projects include (1) unsuitability of design for the MiC method, (2) late involvement of suppliers, fabricators, and contractors, (3) inaccurate information, defective design, and change order , (4) design information gap between the designer and fabricator, and (5) lack of bespoke MiC design codes, guidelines and standards. Thus, it is imperative for MiC project design teams to carefully consider the suitability of the design for modular solutions early upfront, engage, and encourage the sharing of accurate information among the designers, engineers, suppliers, fabricators, and contractors. The findings also demonstrate the relevance of adhering to local building codes and early freezing of the design. A Pearson's correlation analysis revealed that 26 of the 55 correlations were statistically significant at $95 \%$ confidence interval, indicating that the DRFs for MIC projects have relationships. The analysis 
Wuni et al. (2021). "Exploring the design risk factors for modular integrated construction projects". Construction Innovation. (Accepted)

revealed that $\mathrm{DRF}$ for $\mathrm{MiC}$ projects, including (i) inadequate design planning, (ii) inaccurate information, defective design, and change order, (iii) design rework, and (iv) design information gap between the designer and fabricator have strong statistically positive significant relationships. This correlation means that an increase in the impact of one will increase the probability of occurrence and severity of the correlated DRFs. As such, some of the DRFs have dynamic linkages that should be considered during MiC project design risk planning.

Despite the realization of the research aim, there are some limitations to the results that are worthy of consideration. First, although statistically adequate, the sample size was small and may not capture the most dominant perspectives of MiC experts on the relative significance of the DRFs for $\mathrm{MiC}$ projects. Also, the disproportionate representation of academics (78.6\%) and industry practitioners $(21.4 \%)$ could make the results reflect the opinions of the academics rather than both. Nevertheless, the results provide a useful snapshot and panoramic views of MiC experts on the relative significance of the DRFs for MiC projects. Second, the investigated DRFs may not be exhaustive and require improvement in future research. Third, the generalized analysis overlooked the sensitivities of the DRFs to different territories and project types. Nonetheless, the results provide a basis for comparison with more specific territorial rankings of the DRFs for MiC projects. Fourth, despite its widespread usage in academic research, the Likert scale used in this study is associated with subjectivity in assigning grades to the risk factors and can be significantly influenced by the experience and knowledge of the respondents. The impact of the inherent subjectivity of the Likert scale can be minimized in future studies using fuzzy logic to analyse the survey-based dataset. Future research should increase the sample size and explore the dynamic linkages of the DRFs for MiC projects in a specific context using artificial neural networks and system dynamics. 
Wuni et al. (2021). "Exploring the design risk factors for modular integrated construction projects". Construction Innovation. (Accepted)

\section{References}

Ameyaw, E.E. and Chan, A.P.C. (2015), "Evaluation and ranking of risk factors in public-private partnership water supply projects in developing countries using fuzzy synthetic evaluation approach”, Expert Systems with Applications, Elsevier Ltd, Vol. 42 No. 12, pp. 5102-5116.

Ayinla, K.O., Cheung, F. and Tawil, A.R. (2019), "Demystifying the concept of offsite manufacturing method: Towards a robust definition and classification system", Construction Innovation, available at:https://doi.org/10.1108/CI-07-2019-0064.

Baloi, D. and Price, A.D.F. (2003), "Modelling global risk factors affecting construction cost performance", International Journal of Project Management, Vol. 21 No. 4, pp. 261-269.

Blismas, N.G., Pendlebury, M., Gibb, A.G.F. and Pasquire, C. (2005), "Constraints to the use of Off-site production on construction projects", Architectural Engineering and Design Management, Vol. 1 No. 3, pp. 153-162.

Blismas, N.G. and Wakefield, R. (2009), "Drivers, constraints and the future of offsite manufacture in Australia", Construction Innovation, Vol. 9 No. 1, pp. 72-83.

Boothroyd, G. (1994), "Product design for manufacture and assembly", Computer-Aided Design, Vol. 26 No. 7, pp. 505-520.

Buchanan, R. (1992), “Wicked Problems in Design Thinking”, Design Issues, Vol. 8 No. 2, pp. 521.

Chou, Y.-M., Polansky, A.M. and Mason, R.L. (1998), "Transforming Non-Normal Data to Normality in Statistical Process Control”, Journal of Quality Technology, Vol. 30 No. 2, pp. $133-141$.

Enshassi, M.S.A., Walbridge, S., West, J.S. and Haas, C.T. (2019), "Integrated Risk Management Framework for Tolerance-Based Mitigation Strategy Decision Support in Modular Construction Projects", Journal of Management in Engineering, Vol. 35 No. 4, p. 05019004.

Gao, S., Jin, R. and Lu, W. (2019), "Design for manufacture and assembly in construction: a review”, Building Research and Information, Taylor \& Francis, Vol. 0 No. 0, pp. 1-13.

Gibb, A.G.F. and Isack, F. (2001), "Client Drivers for Construction Projects”, Engineering Construction and Architectural Management, Vol. 8 No. 1, pp. 46-58.

Horner, M., El-haram, M. and Vitali, D. (2019), Advanced Industrialised Methods for the Construction of Homes (AIMCH) - Work Package 2: Productivity Mapping and Literature 
Wuni et al. (2021). "Exploring the design risk factors for modular integrated construction projects". Construction Innovation. (Accepted)

Review, Scotland.

Hwang, B.-G., Shan, M. and Looi, K.Y. (2018), "Knowledge-based decision support system for prefabricated prefinished volumetric construction", Automation in Construction, Elsevier, Vol. 94 No. July, pp. 168-178.

Kim, T.K. (2015), “T test as a parametric statistic”, Korean Journal of Anesthesiology, Vol. 68 No. 6, pp. 540-546.

KPMG. (2016), Smart Construction: How Offsite Manufacturing Can Transform Our Industry, United Kingdom, available at: https://www.buildoffsite.com/content/uploads/2016/08/KPMG-Smart-Construction.pdf.

Lee, J.S. and Kim, Y.S. (2017), “Analysis of cost-increasing risk factors in modular construction in Korea using FMEA”, KSCE Journal of Civil Engineering, Vol. 21 No. 6, pp. 1999-2010.

Li, C.Z., Hong, J., Xue, F., Shen, G.Q., Xu, X. and Mok, M.K. (2016), "Schedule risks in prefabrication housing production in Hong Kong: a social network analysis", Journal of Cleaner Production, Elsevier Ltd, Vol. 134 No. Part B, pp. 482-494.

Li, C.Z., Shen, G.Q., Xue, F., Luo, L., Xu, X. and Sommer, L. (2017), “Schedule risk modeling in prefabrication housing production”, Journal of Cleaner Production, Elsevier Ltd, Vol. 153, pp. 692-706.

Li, C.Z., Zhong, R.Y., Xue, F., Xu, G., Chen, K., Huang, G.G. and Shen, G.Q. (2017), “Integrating RFID and BIM technologies for mitigating risks and improving schedule performance of prefabricated house construction”, Journal of Cleaner Production, Elsevier Ltd, Vol. 165, pp. $1048-1062$.

Nachar, N. (2008), "The Mann-Whitney U: A Test for Assessing Whether Two Independent Samples Come from the Same Distribution", Tutorials in Quantitative Methods for Psychology, Vol. 4 No. 1, pp. 13-20.

Nibbelink, J.G., Sutrisna, M. and Zaman, A.U. (2017), "Unlocking the potential of early contractor involvement in reducing design risks in commercial building refurbishment projects-a Western Australian perspective", Architectural Engineering and Design Management, Taylor \& Francis, Vol. 13 No. 6, pp. 439-456.

Osei-Kyei, R., Chan, A.P.C., Javed, A.A. and Ameyaw, E.E. (2017), “Critical success criteria for public-private partnership projects: international experts' opinion", International Journal of Strategic Property Management, Vol. 21 No. 1, pp. 87-100. 
Wuni et al. (2021). "Exploring the design risk factors for modular integrated construction projects". Construction Innovation. (Accepted)

Ott, R.L. and Longnecker, M. (2016), An Introduction to Statistical Methods and Data Analysis, 7th Editio., Cengage Learning, Boston, MA.

Project Management Institute. (2017), A Guide to the Project Management Body of Knowledge (PMBOK Guide), 6th Editio., Project Management Institute, Newton Square, Pennsylvania, available at:https://doi.org/10.1002/pmj.21345.

Sutrisna, M. and Goulding, J. (2019), "Managing information flow and design processes to reduce design risks in offsite construction projects", Engineering, Construction and Architectural Management, Vol. 26 No. 2, pp. 267-284.

Sutrisna, M., Ramanayaka, C.D.D. and Goulding, J.S. (2018), "Developing work breakdown structure matrix for managing offsite construction projects", Architectural Engineering and Design Management, Taylor \& Francis, Vol. 14 No. 5, pp. 381-397.

van Vuuren, T.J. and Middleton, C. (2020), Methodology for Quantifying the Benefits of Offsite Construction, London, UK.

Wuni, I.Y. and Shen, G.Q. (2020a), "Barriers to the adoption of modular integrated construction: Systematic review and meta-analysis, integrated conceptual framework, and strategies", Journal of Cleaner Production, Elsevier B.V., Vol. 249 No. March, p. 119347.

Wuni, I.Y. and Shen, G.Q. (2020b), "Critical success factors for management of the early stages of prefabricated prefinished volumetric construction project life cycle", Engineering, Construction and Architectural Management, Vol. 27 No. 9, pp. 2315-2333.

Wuni, I.Y. and Shen, G.Q. (2020c), "Fuzzy modelling of the critical failure factors for modular integrated construction projects", Journal of Cleaner Production, Elsevier Ltd, Vol. 264C No. August, p. 121595.

Wuni, I.Y., Shen, G.Q., Osei-Kyei, R. and Agyeman-Yeboah, S. (2020), "Modelling the critical risk factors for modular integrated construction projects", International Journal of Construction Management, Taylor \& Francis, Vol. Early Cite, pp. 1-14.

Zhang, X. (2005), “Critical success factors for public-private partnerships in infrastructure development”, Journal of Construction Engineering and Management, Vol. 131 No. 1, pp. $3-14$. 